\title{
Justicia digital, acceso a internet y protección de datos personales ${ }^{1}$
}

\author{
Mónica María Bustamante Rúa² \\ Universidad de Medellín \\ mmbustamante@udem.edu.co \\ Código ORCID: https://orcid.org/0000-0002-1029-1468 \\ Jorge Iván Marín Tapiero ${ }^{3}$ \\ Universidad de Medellín \\ ivanmt095@gmail.com \\ Código ORCID: https://orcid.org/0000-0001-9657-062X
}

\section{Resumen:}

En este artículo se analiza el concepto de justicia digital, diferenciándolo de nociones similares como justicia electrónica, e-justice o justicia abierta. Además, se examina el principio de publicidad del proceso y el derecho de acceso al internet desde una perspectiva internacional. Posteriormente, se abordan de forma sucinta las Reglas de Heredia del 9 de julio de 2003, adoptadas como pautas mínimas para la difusión de información judicial en internet. Concluimos con los retos que representa la digitalización de la justicia y las alternativas para garantizar un umbral de mínimo respeto por los derechos de los administrados.

Palabras clave: justicia digital; acceso a internet; publicidad; protección de datos personales; expediente digital

\section{Abstract:}

The article analyzes the concept of digital justice, differentiating it from similar notions such as electronic justice, e-justice or open justice. In addition, it examines the principle of publicity of the process and the right of internet access from an international perspective. Subsequently, the Heredia Rules adopted as minimum guidelines for the dissemination of judicial information on the Internet, are briefly addressed. We conclude with the challenges that the digitalization of justice represents and the alternatives to guarantee a minimum threshold of respect for the rights of the justice users.

Keywords: digital justice; internet access; publicity; data protection; digital file

\footnotetext{
'El artículo es un producto preliminar de la investigación "Garantía del derecho a la protección de los datos personales de cara a la publicidad procesal en la justicia digital" ejecutado en la Maestría en Derecho Procesal Contemporáneo de la Universidad de Medellín (Colombia). El escrito es original y de autoría propia, respeta los derechos de autor y su texto es inédito, no corresponde a reproducción de uno ya publicado por los autores.
} 


\section{Introducción}

El contexto contemporáneo de la "Cuarta Revolución Industrial", impulsada por la sociedad de la información y del conocimiento, ha tenido incidencia en variedad de esferas de las relaciones humanas, tanto en la cultura como en la economía, la política y el Derecho. En este último, no solo el derecho sustancial ha evolucionado conforme a las nuevas dinámicas de las Tecnologías de la Información y las Comunicaciones (en adelante, TIC), sino que también ha tenido incidencia en el campo del derecho procesal. En Colombia, ya desde la Ley 270 de 1996 se había consagrado el deber de incorporar el uso de tecnología de avanzada en la prestación del servicio público de administrar justicia, enfocada principalmente en mejorar la práctica de las pruebas, la formación, conservación y reproducción de los expedientes, la interoperabilidad entre despachos y el funcionamiento razonable de los sistemas de información de la Rama Judicial.

Desde 1996 hasta 2020 no se había logrado mayor progreso en el cumplimiento del imperativo legal de incorporar el uso de las TIC en el funcionamiento del aparato jurisdiccional. La pandemia del COVID-19 constituyó el mayor aliciente para ello. Así, a través del Decreto Legislativo 806 del 4 de junio de 2020, el Gobierno Nacional adoptó medidas ad hoc para un período de dos años que implementan el uso de las TIC en las actuaciones judiciales. Con ello, se propugnó agilizar los procesos y flexibilizar la atención a los usuarios del servicio de justicia en el marco del Estado de Emergencia Económica, Social y Ecológica declarado a través del Decreto Legislativo 637 del 6 de mayo de 2020.

A las complejidades que suscita la implementación de las TIC en la administración de justicia deberán aunarse las propias de la premura con que tuvo que adaptar Colombia un sistema de justicia digital de cara al ciudadano, de manera tal que no cercene sus derechos ni garantías procesales. Por ello, además de los retos que representa en materia procedimental y probatoria, destacan los riesgos que genera la exclusión digital para el acceso a la justicia y el tratamiento de datos personales en el proceso jurisdiccional electrónico, tanto desde la fase de iniciación hasta la posterior a la sentencia.

Entre los últimos destacan los alcances del principio de publicidad que debe imperar en las actuaciones judiciales (a la luz del artículo 228 Constitucional y 8 Convencional); la garantía de los derechos a la intimidad, la privacidad y el hábeas data de las personas inmersas en procesos jurisdiccionales en armonía con la publicidad de las actuaciones; los instrumentos adecuados para la publicidad del proceso (canales institucionales, redes sociales, etc.); y los controles de los que pueden valerse los usuarios del sistema para la garantía de sus derechos.

Al respecto, tanto el artículo 228 de la Constitución Política de 1991 como el numeral 8 del artículo 5 de la Convención Americana sobre Derechos Humanos (CADH) reconocen la publicidad como una garantía mínima que deben observar los operadores judiciales en aras de asegurar su transparencia e imparcialidad. No obstante, como característica común a la mayoría de libertades y derechos, no es absoluta, y se permite su restricción cuando las circunstancias así lo requieran. Pero ¿a qué se refiere la norma cuando avala las restricciones de la publicidad procesal según el mérito de las circunstancias? Al tenor del citado artículo de la $\mathrm{CADH}$, podrá hacerse "para preservar los intereses de la justicia" (Organización de los Estados Americanos, 1969), sin precisar cuáles son dichos intereses ni qué medidas podrá adoptar el juez ni sobre cuáles sujetos. Como desarrollo de dicha facultad o deber es habitual que se realicen audiencias a puerta cerrada o se consagre la reserva -no para la parte- del sumario durante la fase de investigación como concreción de esta garantía convencional.

Son medidas que podrían adoptarse mutatis mutandi para la plena observancia del principio en el desarrollo de las audiencias y diligencias virtuales, dada la ausencia de instrumentos normativos que permitan saldar esta inquietud en el Decreto Legislativo 806 de 2020. Dicha norma se limita a enunciar que se adoptarán las medidas necesarias -nuevamente un numerus apertus 
absolutamente indeterminado- para garantizar el debido proceso, la publicidad y el derecho de contradicción en la aplicación de las TIC. Por ello, el parágrafo 1 del artículo 2 del Decreto Legislativo 806 de 2020 consagró que "Para el efecto, las autoridades judiciales procurarán la efectiva comunicación virtual con los usuarios de la administración de justicia y adoptarán las medidas pertinentes para que puedan conocer las decisiones y ejercer sus derechos".

Esta consagración pareciese apuntar a la garantía de la publicidad únicamente de cara a las partes sin considerar instrumentos que permitan satisfacer la publicidad de cara a la comunidad o ciudadanía en general. Para ello, algunos despachos judiciales han optado por trasladar sus audiencias al escenario de las redes sociales, transmitiéndolas vía streaming o permitiendo el acceso libre a las grabaciones. Así, en un intento de máxima optimización del principio de publicidad se vulnera, a la vez, la privacidad e intimidad de las partes y demás intervinientes.

Asimismo, no debe perderse de vista que, si bien el proceso judicial es por naturaleza público, no toda la información que en él se vierte reviste la misma naturaleza, pues podrán encontrarse datos privados, semiprivados y otros sensibles tanto en los actos introductorios como en los de impulso, desarrollo y aun en los de decisión. Esta situación se torna más compleja si se considera que dichos datos conciernen principal, pero no exclusivamente, a las partes, sino que pueden referirse a los coadyuvantes, llamados de oficio, testigos, peritos y demás sujetos procesales con capacidad para intervenir en un juicio.

¿Bastará entonces el parágrafo 1 del artículo 2 del Decreto Legislativo 806 de 2020 o el literal d del artículo 6 de la Ley 1581 de 2012 para conciliar la protección de los datos propios de la esfera íntima de las personas con el deber de publicidad de todo proceso judicial?

Por otra parte, si bien se ha reconocido el acceso al internet como un derecho humano y, en algunas latitudes, como derecho fundamental, las dificultades para la democratización de la tecnología en diversos países han conllevado a la vulneración simultánea de este derecho y los de tutela jurisdiccional efectiva y el acceso a la justicia de los llamados "excluidos digitales".

Así, con el propósito de vislumbrar algunas respuestas a los retos planteados, en este artículo se analizará el derecho de acceso a internet como derecho fundamental; luego se examinará el concepto de justicia digital, diferenciándolo de nociones similares como justicia electrónica, e-justice o justicia abierta, y el principio de publicidad del proceso desde una perspectiva internacional. Posteriormente, se abordarán de forma sucinta las Reglas de Heredia del 9 de julio de 2003, adoptadas como pautas mínimas para la difusión de información judicial en internet. Finalmente, se concluirá con los retos que representan la digitalización de la justicia y las alternativas para garantizar un umbral de mínimo respeto por los derechos de los administrados.

\section{Derecho de acceso al internet: análisis desde una perspectiva internacional}

Las TIC han impactado en el alcance de los derechos fundamentales y sus mecanismos de protección. En ese sentido, se discute desde la doctrina el surgimiento de un nuevo derecho fundamental: el de acceso a internet.

Miranda (2016) señala que el surgimiento de "nuevos derechos" obedece a diferentes factores, entre ellos, la globalización económica y política, los avances científicos y tecnológicos, la internacionalización de los derechos humanos y las garantías para su tutela, y la existencia de problemáticas comunes. En esa medida, indica que el acceso a internet puede ser considerado como un derecho social que debe ser satisfecho con prestaciones públicas, así como se reconocen los derechos a la educación y la salud pública. Afirma también que el acceso a internet es

"(...) un servicio universal que las instituciones nacionales deben garantizar a sus ciudadanos a través de inversiones estatales, políticas, sociales y educativas, elecciones 
de gasto público. En efecto, cada vez más el acceso a la red de internet y el desarrollo de esa actividad constituye el modo en el cual el sujeto se relaciona con los poderes públicos, y por lo tanto, ejerce sus derechos" (Miranda, 2016, p. 9).

Estas ideas tienen sustento en algunos antecedentes de alcance internacional:

\begin{tabular}{|c|c|}
\hline $\begin{array}{l}\text { Convención Internacional } \\
\text { sobre los derechos de las } \\
\text { personas con discapacidad } \\
\text { de la Organización de } \\
\text { Naciones Unidas (ONU) }\end{array}$ & $\begin{array}{l}\text { En su artículo } 21 \text { inciso c) dispone que los Estados } \\
\text { parte deben adoptar medidas pertinentes para que las } \\
\text { personas con discapacidad puedan ejercer el derecho a } \\
\text { la libertad de expresión y opinión, incluida la libertad de } \\
\text { recabar, recibir y facilitar información; para ello, plantea } \\
\text { la necesidad de alentar a las entidades privadas que } \\
\text { prestan servicios públicos en general, incluso mediante } \\
\text { internet, a proporcionar información y servicios en } \\
\text { formatos que las personas con discapacidad puedan } \\
\text { utilizar. }\end{array}$ \\
\hline $\begin{array}{l}\text { Resolución del } 18 \text { de abril } \\
\text { de } 2008 \text { del } \\
\text { Europeo }\end{array}$ & $\begin{array}{l}\text { expresión cultural, el acceso al cor } \\
\text { participación democrática. Por ello, cc } \\
\text { importante evitar la adopción de mec } \\
\text { con los derechos civiles, los derechos }\end{array}$ \\
\hline $\begin{array}{c}\text { de la } \\
\text { aciones }\end{array}$ & $\begin{array}{l}\text { por } \\
\text { y el }\end{array}$ \\
\hline $\begin{array}{lr}\text { Sentencia } & \text { Nro. } \\
\text { DC de } 10 \text { de junio de } 2009.58 \\
\text { Consejo } & \text { Constitucional } \\
\text { Francés } & \end{array}$ & $\begin{array}{l}\text { los Derechos del Hombre y } \\
\text { que tutela la libre comunicac } \\
\text { opiniones. }\end{array}$ \\
\hline $\begin{array}{l}\text { ro. } 12790-2010 . \\
\text { itucional de la } \\
\text { ema de Justicia } \\
\text { ca }\end{array}$ & $\begin{array}{l}\text { el acceso a internet como un derecho } \\
\text { al. }\end{array}$ \\
\hline $\begin{array}{l}\text { Resolución del Consejo } \\
\text { de Derechos Humanos } \\
\text { de Naciones Unidas en la } \\
\text { Resolución del } 29 \text { de junio } \\
\text { del } 2012 \text { sobre promoción, } \\
\text { protección y difusión de } \\
\text { los derechos humanos en } \\
\text { internet }\end{array}$ & $\begin{array}{l}\text { Reconoce la naturaleza mundial y abierta de Internet } \\
\text { comofuerzaimpulsora de laaceleración delos progresos } \\
\text { hacia el desarrollo en sus distintas formas y exhorta a } \\
\text { los Estados a que promuevan y faciliten el acceso } \\
\text { a internet y la cooperación internacional encaminada } \\
\text { al desarrollo de los medios de comunicación y los } \\
\text { servicios de información y comunicación en todos los } \\
\text { países. }\end{array}$ \\
\hline
\end{tabular}

El sustento del derecho de acceso a internet parte de las ideas de acceso, no discriminación y pluralismo. De allí que la accesibilidad a internet impone la adopción de las siguientes medidas: a) positivas de inclusión, lo que exige el cierre de la brecha digital; b) diseño de planes para asegurar la infraestructura, los servicios y los recursos tecnológicos para garantizar progresivamente el acceso universal; c) de prohibición de bloqueo o limitación de acceso a internet.

Se considera por la Asamblea General de las Naciones Unidas (2011, p. 24) que el internet es

“(...) un instrumento indispensable para ejercer diversos derechos humanos, luchar contra la desigualdad y acelerar el desarrollo y el progreso humano, la meta del acceso universal a Internet ha de ser prioritaria para todos los Estados. En consecuencia, cada uno debe elaborar una política eficaz y concreta en consulta con personas de todos los sectores de la sociedad, entre ellos el sector privado, y con los ministerios gubernamentales competentes, 
a fin de que Internet resulte ampliamente disponible, accesible y asequible para todos los sectores de la población".

Lo anterior exige la reducción de la brecha digital en justicia digital que comprende: a) brecha de acceso, que se refiere a las posibilidades reales que tienen las personas de acceder a los recursos tecnológicos y al internet; b) brecha de uso, que hace referencia a la falta de competencias digitales y que limita la gestión tecnológica adecuada; y c) la brecha de calidad de uso, que refiere a la falta de conocimiento para hacer un buen uso de la red, lo que limita el acceso a la información de calidad.

Incluso desde la doctrina se plantea que el acceso a internet reúne algunas de las características para ser considerado un derecho fundamental, dado que se debe reconocer por igual y sin discriminación, podría comportar un deber internacional y universal, con reconocimiento progresivo, supratemporal e indivisible. Sin embargo, no existe consenso al respecto, Prince Torres (2020) plantea que la noción de derecho fundamental de acceso a internet existe solo en un plano doctrinal y jurídico interno de algunos países, pero que internacionalmente no se reconoce como hard law la existencia de este derecho, aunque no niega la posibilidad de que a futuro, en la esfera interestatal, llegue a reconocerse por instrumentos de derecho teniendo en consideración que el mundo jurídico es dinámico y condicionado a los fenómenos sociales.

Esta cuestión no se detiene aquí, en Latinoamérica. Allende Pérez de Arce (2019) plantea el debate de cómo la propuesta de introducir tribunales civiles en línea no debe afectar el derecho de acceder a la justicia de quienes no están conectados a internet. Puntualmente entiende que un tribunal en línea es

“(...) aquella plataforma radicada en internet en la que se someten a conocimiento y decisión de un juez las disputas de menor cuantía. Es un único tribunal -una plataformapara conocer de todos los asuntos que se promuevan en su territorio jurisdiccional. El procedimiento es flexible y fácil de utilizar, totalmente digital, al punto de que no requiere la intervención de abogados, ni la existencia de un edificio físico - al menos para la atención de público-. El enfoque principal de este tribunal es la búsqueda de una solución amistosa entre las partes, por medio de negociaciones mantenidas vía web, y solo en caso de fallar éstas interviene el juez y resuelve la disputa" (Allende Pérez de Arce, 2019, p.186).

Se plantean argumentos sobre la necesidad de implementar tribunales de justicia en línea para la solución de conflictos civiles de menor cuantía. Entre los principales argumentos se encuentran: a) la reducción de costos asociados al proceso, dado que no se requiere la intervención o asesoría de un abogado; b) la agilización de los procesos porque las notificaciones se surten por correo electrónico u otro medio digital, la práctica de prueba testimonial es por medio virtual y la presentación de documentos a través de la carga por medio de plataforma web; c) en razón al crecimiento exponencial de comercio electrónico con el consecuente incremento de disputas y no todas cuentan con mecanismos propios de solución de controversias en línea; d) la protección del derecho a la tutela judicial efectiva de aquellas personas cuyas disputas no están llegando a los tribunales, teniendo en cuenta los costos asociados a los procedimientos civiles y al tiempo del trámite.

A pesar de que existen argumentos a favor de los tribunales en línea, también existen preocupaciones en relación con a) los sistemas de seguridad informática y los riesgos de crackeo y ciberataques; b) los costos de implementación de la infraestructura tecnológica que requiere un tribunal en línea; c) la brecha digital para el acceso a internet por razones geográficas, culturales o económicas.

La última es la principal preocupación, dado que un ciudadano que no pueda acceder a internet, no podría acceder al tribunal en línea. Esto actualmente sucede en muchos países que han implementado procesos electrónicos, expedientes digitales y audiencias virtuales, siendo evidentes las limitaciones de los ciudadanos por diferentes factores para acceder a internet. De allí que 
el debate frente el reconocimiento del acceso a internet como derecho fundamental y derecho humano tenga razón de ser de cara a la tutela jurisdiccional efectiva y el acceso a la justicia. En consecuencia, en un contexto de justicia digital, la vulneración del derecho de acceso a internet acarreará, a su vez, el desconocimiento del derecho de acción y de una tutela jurisdiccional efectiva.

\section{Justicia digital, e-justice, justicia electrónica y justicia abierta}

Echavarría (2020, p. 408) entiende la justicia digital como "la administración de justicia en el entorno digital, supone, entonces, la administración o gestión de la justicia con la mediación de la tecnología, para el entorno digital en el que ahora se desarrolla". Para lo cual, esta autora llama la atención sobre la ausencia de sinonimia entre los términos "justicia digital", "e-justice", "open justice" y "justicia electrónica", encontrando en la gestión tecnológica la clave para diferenciar la justicia digital de los demás conceptos. Así, "la justicia digital requiere de la gestión tecnológica. Esta variable resulta fundamental no solo para la comprensión del fenómeno, sino también para la creación de una verdadera política de justicia digital a nivel nacional” (Echavarría, 2020, p. 409).

En consecuencia, la justicia digital supera el mero uso de los avances tecnológicos por los despachos judiciales, los conocimientos operativos para realizar audiencias por videollamadas, como lo pretenden las nociones de e-justice (Amrani-Mekki, 2008, p. 35) y justicia electrónica, y exige la estructuración de una verdadera gestión tecnológica en el aparato jurisdiccional del Estado, que le permita su funcionamiento fuera de los entornos físicos y analógicos. Entre las características de lo que Amrani-Mekki (2008, p. 35) denomina e-justice, destacan:

a. Equipamiento adecuado de los despachos judiciales, acompañado de una pedagogía tecnológica dirigida a los jueces y auxiliares de la justicia;

b. Uso del escrito electrónico, encaminado a la implementación de una justicia sin papel (paperless justice);

c. Uso de la videoconferencia, reduciendo los costos de desplazamiento y facilitando las comisiones judiciales.

La incorporación de las TIC constituye una oportunidad para que el aparato jurisdiccional fortalezca los principios de la tutela judicial efectiva, basada en un proceso justo y equitativo con mayor cercanía entre el juez y el ciudadano. "La proximidad al juez no es tan solo física. El acercamiento de la justicia al justiciable puede realizarse gracias al uso de las nuevas tecnologías" (Amrani-Mekki, 2008, p. 11). La formación de los expedientes judiciales que permitan ejercer el derecho de acción desde la distancia, valiéndose de los escenarios virtuales y con apoyo en los documentos electrónicos, constituye un paso necesario para la adaptación de las estructuras jurídicas a las tendencias de la contemporaneidad, con lo cual se procura superar el umbral de la simple incorporación de las TIC como apoyo del poder judicial.

\section{Principio de publicidad procesal}

La publicidad del proceso ha sido reconocida como un derecho humano, contenido en los artículos 11 numeral 1 de la Declaración Universal de Derechos Humanos de 1948 y 14 numeral 1 del Pacto Internacional de Derechos Civiles y Políticos de 1966. En el contexto americano, el numeral 5 del artículo 8 de la Convención Americana sobre Derechos Humanos de 1969 (en adelante, CADH) lo incorpora como una garantía procesal cuya observancia es de obligatoria exigencia para todos los Estados parte. Por ello, para Picó i Junoy (2012, p. 139) "la publicidad del proceso ocupa una posición institucional en el Estado de Derecho que la convierte en una de las condiciones de la legalidad constitucional de la Administración de justicia". En el ámbito doméstico, fue consagrado como un derecho fundamental en el artículo 29 Superior. 
Este derecho humano y fundamental exige que el conocimiento del proceso trascienda el círculo de partes e intervinientes, a partir de lo cual puede tener una proyección de cara a la comunidad en general.

"Esta proyección no puede hacerse efectiva más que con la asistencia del público y de los medios de comunicación, en cuanto tal presencia les permite adquirir la información en su misma fuente y transmitirla a cuantos, por una serie de imperativos de espacio, de tiempo, de distancia, de quehacer, etc., están en la imposibilidad de hacerlo" (Picó i Junoy, 2012, p. 139).

En consecuencia, la publicidad goza de una doble connotación jurídica constitucional: es fin y principio a la vez. Propicia la concreción de los fines del Estado al permitir la existencia de ciudadanos informados que participen en las decisiones que los afectan, "por cuanto permite enterar a la comunidad y mantenerla informada sobre los hechos que ocurren a su alrededor, así como de los fundamentos que motivan las decisiones adoptadas por las autoridades" (Corte Constitucional, Sentencia C-096 de 2001). Así se forma un ciudadano activo, deliberante, autónomo y crítico que pueda ejercer un debido control de la actividad del Estado. La publicidad se constituye en elemento fundamental para el cumplimiento del pilar democrático sobre el que se erige la estructura de funcionamiento del Estado colombiano, el cual requiere de la existencia de una opinión pública plenamente informada. "La mirada pública puede quizá incomodar a los funcionarios, pero resulta esencial para el mantenimiento del sistema democrático" (Corte Constitucional, Sentencia C-053 de 1995).

De allí que Picó i Junoy (2012, p. 140) reconozca una doble finalidad de este principio: i) la de proteger a las partes de una justicia sustraída al control público; y ii) la de mantener la confianza de la comunidad en el aparato jurisdiccional del Estado.

Planteamientos que han sido de recibo por la Corte Interamericana de Derechos Humanos (en adelante, Corte IDH), quien, en el caso Palamara Iribarne vs. Chile (2005, párrafo 168), manifestó que:

"La publicidad del proceso tiene la función de proscribir la administración de justicia secreta, someterla al escrutinio de las partes y del público y se relaciona con la necesidad de la transparencia e imparcialidad de las decisiones que se tomen. Además, es un medio por el cual se fomenta la confianza en los tribunales de justicia. La publicidad hace referencia específica al acceso a la información del proceso que tengan las partes e incluso los terceros".

En consecuencia, la publicidad procesal funge a la vez como derecho, principio y medio del juicio, que asegura la transparencia e imparcialidad de los órganos jurisdiccionales. Como derecho y principio, no es absoluto ni ilimitado, y se permite su restricción cuando las circunstancias lo requieran. "Excepciones que, en todo caso, deberán estar siempre autorizadas por ley" (Picó i Junoy, 2012, p. 140). De allí que se permita el acceso de la comunidad en general y de los medios de comunicación a la celebración de las audiencias, que puede ser limitado por razones de orden público u otros imperativos expresamente consagrados en la ley.

Rodríguez Rescia (1998) considera que esta garantía se relaciona con el principio procesal de la oralidad, por cuanto, "la oralidad es una forma de establecer una actividad contralora de las decisiones judiciales por medio de su transparencia" (Rodríguez Rescia, 1998, p. 1315). No obstante, no puede colegirse su equivalencia absoluta, como lo reconoció la Corte IDH en el caso Girón y Otro vs. Guatemala (2019, párrafo 122).

\section{Derecho a la protección de datos personales: análisis desde una perspectiva internacional}

La "protección de datos personales" (data protection) ha sido un tema de creciente interés a nivel nacional e internacional. Siguiendo a Bygrave (2010), si bien desde la doctrina y la legislación internacional se 
le ha relacionado con la "intimidad" y la "privacidad" (privacy) de las personas, "sería erróneo asumir que los conceptos de «protección de datos» y «privacidad» son completamente sinónimos. Aunque están estrechamente vinculados, no son idénticos" (Bygrave, 2010, p. 168). Así, la "protección de datos" hace referencia a una gama de derechos más amplia que los de intimidad y privacidad en escenarios informáticos e informacionales, superando las esferas espaciales o físicas de la intimidad.

En consecuencia, Bygrave (2010) entiende a la protección de datos como "un conjunto de normas que sirven a una gama más amplia de intereses que la simple protección de la privacidad". En contraste con esta noción, para Doneda (2011), Díaz (2013) y Gacitúa (2014), la protección de datos personales se erige como un derecho de naturaleza fundamental, autónomo e independiente de otros derechos fundamentales, cuyos límites se encuentran en los demás derechos de igual naturaleza y los bienes jurídicos constitucionalmente protegidos. Este derecho consiste en

“(...) un poder de disposición y control de los datos personales, que se concreta en la facultad de consentir sobre la recogida y el uso de sus datos personales y a saber de los mismos: saber, por tanto, qué datos se poseen sobre su persona y qué destino han tenido. Comprende, entre otros aspectos, la oposición al ciudadano a que determinados datos personales sean utilizados para fines distintos de aquel legítimo que justificó su obtención. Además, comprende el derecho a ser informados, a consentir, así como los derechos de acceso, rectificación y cancelación" (Gacitúa, 2014, pp. 82-83).

Por su parte, la Red Iberoamericana de Protección de Datos $(2017$, p. 8) define los datos personales como "cualquier información concerniente a una persona física identificada o identificable, expresada en forma numérica, alfabética, gráfica, fotográfica, alfanumérica, acústica o de cualquier otro tipo". Estos datos podrán ser públicos, semiprivados, privados o sensibles, cuya área de interés se reduce desde la comunidad en general hasta única y exclusivamente el titular de la información.

\section{Justicia digital y protección de datos personales: retos y dificultades}

EI COVID-19 generó una serie de dificultades para el funcionamiento del aparato estatal por medios digitales, especialmente para su sistema jurisdiccional, que debe garantizar procesos respetuosos de derechos y garantías constitucionales y convencionales, edificados sobre cimientos que permitan la prevención estratégica de daños antijurídicos derivados de la facilidad de transferencia de la información por medios tecnológicos en detrimento de la intimidad de los administrados. En las vísperas del nuevo siglo, Chirino (1998) advertía los retos que generaría el derecho a la protección de datos personales para el funcionamiento del moderno proceso penal con la utilización de medios técnicos y tecnológicos que le permitieran alcanzar eficiencia y funcionalidad a la administración de justicia. Según este autor, la protección de datos personales

“(...) se observa como un obstáculo o barrera para alcanzar los fines de la política de prevención y de eficientismo de la administración de justicia, ya que, según los defensores de estas tendencias populistas en el derecho procesal, solo mediante el acopio de ingentes cantidades de información sobre las personas es que posible garantizar un amplio esfuerzo en el combate de la criminalidad y una mejoría sustancial del trabajo de las agencias de control penal" (Chirino, 1998, p. 21).

Por lo cual, el autor advertía la necesidad de una "re-programación funcional" del derecho a la protección de datos personales de cara al proceso penal, encontrando en los principios de necesidad, razonabilidad y proporcionalidad de las medidas a adoptar los límites de dichas actuaciones. En consecuencia,

"El procesamiento de datos en sede de la administración de la justicia penal que se realiza con fines imprecisos o no definidos debe ser, entonces, prohibida, ya que, al no 
contarse con un fin específico para el tratamiento de los datos, no podrá valorarse ni el alcance del tratamiento, como si en efecto fue alcanzado el fin de ese tratamiento" (Chirino, 1998, p. 26).

Si bien las experiencias de justicia electrónica y justicia digital en Colombia son aún frugales, la experiencia comparada permite avizorar los retos que su implementación resulta para la protección de los datos personales. Así, a partir de la experiencia brasileña, en Linden, Piñeiro y Finger (2011, p. 50) señalaban que

"En una mirada prospectiva, debe existir una preocupación estatal para que germine la percepción de que, como individuos y como sociedad, frente a las dimensiones digitales ahora existentes, vivir en un grupo social democráticamente organizado ha cobrado otro sentido, y esto incluye, en primer lugar, tener una noción clara de lo que realmente significa revelar información hoy. En la misma medida, es importante que exista una protección adecuada frente a sus registros, distorsiones y manipulaciones".

Por su parte, Araújo y de Souza Meirelles advirtieron en 2014 que la publicidad excesiva resulta violatoria de principios constitucionales relevantes, como el de la intimidad y el de la propia personalidad, reconociendo una clara tensión entre los principios y derechos de publicidad procesal y protección de datos personales. Al vislumbrar los cambios que introducen las nuevas tecnologías de la información y las comunicaciones en el proceso jurisdiccional, los autores coligen que, en dicho contexto, los actos procesales pasan a ser concebidos como datos telemáticos, por lo que deberían estar protegidos por la Constitución y por las normas infraconstitucionales (Araújo y de Souza Meirelles, 2014, p. 57). Con ello, llaman la atención de la comunidad internacional respecto a la necesidad de pensar en una agenda sobre la protección de los datos telemáticos envueltos en el proceso judicial electrónico.

"No se puede admitir publicidad excesiva cuando hay datos en un proceso judicial que pueden dañar la dignidad de la persona humana. O todavía, cuando llega a insertarse un determinado dato sensible y que forma parte de un núcleo íntimo y extremadamente personal para el litigante. (Se debe) repensar el proceso a la luz de los Derechos Humanos e insertar en la agenda internacional una política que se ocupe de la protección de la dignidad de la persona humana. Con la informatización y el aumento del acceso a Internet, nuestra preocupación debe ser centrada en el ser humano" (Araújo y de Souza Meirelles, 2014, p. 60).

Con relación al grado de control que permiten las TIC sobre los datos con ellas procesados, Rincón y Ramírez (2017, p. 53) sostienen que "la protección del derecho a la intimidad (...) está íntimamente relacionada con la evolución de los medios de la información y comunicaciones, puesto que a medida que se son más sofisticados, hay menos control del flujo de datos", por lo que una verdadera justicia digital debe responder adecuadamente a las exigencias actuales de la cuarta revolución industrial.

Por ende, en aras de evitar mayores problemas a los que se pretende solucionar, el sistema de justicia digital colombiano deberá saber ponderar el derecho a la protección de datos personales (vinculado con el de privacidad e intimidad) con la garantía de publicidad procesal. Para ello, Bustamante y Marín (2020, pp. 451-452) proponen como base:

a. La capacitación a magistrados, jueces, empleados judiciales, abogados e intervinientes, así como la caracterización de sus recursos tecnológicos y de conectividad.

b. La digitalización de expedientes en condiciones de seguridad informática y con criterios estandarizados a nivel nacional.

c. La delimitación de la política pública para el manejo de datos personales de los abogados, partes e intervinientes. 
d. La creación de un protocolo para la preparación y desarrollo de audiencias públicas a través de plataformas virtuales que establezca alcances y limitaciones a la publicidad de acuerdo con la materia y algunas situaciones especiales.

e. La definición del órgano de certificación de firma digital para magistrados, jueces, secretarios y abogados.

f. La creación de un sistema integrado de gestión de la información que comprenda el manejo del expediente digital y el almacenamiento de las audiencias en condiciones de seguridad.

g. La implementación de tecnologías de avanzada como la inteligencia artificial, el internet de las cosas, el data mining o el big data (en definitiva, los denominados "sistemas jurídicos expertos") para facilitar la decisión judicial y el cumplimiento de las exigencias argumentativas de las providencias.

De este modo, la administración de justicia sembrará las bases para gestionarse tecnológicamente y responder a la doble exigencia de satisfacer el valor justicia en sociedad y ser garante de los derechos fundamentales y las garantías procesales de sus usuarios. Con esto, se permite la consolidación de una cultura de legalidad, modernización y administración de justicia eficiente y eficaz respetuosa de los derechos humanos y fundamentales, en el marco de las dinámicas de la cuarta revolución industrial. Como lo expresa Chirino (1998, p. 22), "el derecho procesal no debe perder su vinculación con los principios constitucionales si no quiere perder su derrotero de defensa de derechos fundamentales, y su legitimación en la presente época de desarrollo de la sociedad de la información".

De igual manera, debe tenerse en consideración que la protección de datos persigue garantizar a su titular un poder de control sobre sus datos personales, sobre su uso y destino, con el propósito de evitar su uso ilícito y lesivo para la dignidad del afectado. Así, el derecho a la intimidad permite excluir ciertos datos de una persona del conocimiento ajeno, verbigracia, a través del expediente digital para resguardar su vida privada de una publicidad no querida o deseada en el marco de la justicia digital.

Ello significa que el derecho a la protección de datos garantiza a los individuos un poder de disposición sobre su información personal, y que impone como consecuencia, para el poder judicial, la prohibición de que se conviertan en fuentes de información sin garantías y reservas legales debidas, así como se le impone el deber de prevenir los riesgos que se puedan derivar del acceso o divulgación indebidas de dicha información disponible.

Respecto al acceso irrestricto al expediente digital, en el que constan datos personales de las partes, en varios países de lberoamérica se han advertido los riesgos que conlleva por la posibilidad de ser captados por los motores de búsqueda, pudiendo ser identificados y discriminados en contrataciones por sus antecedentes crediticios, labores, entre otros. De allí la importancia de instaurar controles de acceso al expediente digital, a través de claves o códigos, que autorice la consulta exclusivamente por las partes, los abogados y los terceros debidamente autorizados y autenticados.

Teniendo en consideración que en un mismo expediente público puede reposar información disponible al público e información de acceso restringido, el reto de la rama judicial del poder público, en cuanto a la publicidad y la protección de datos personales, es precisamente el saber delimitar qué parte de la información del expediente digital se protege y de qué modo, estableciendo las categorías de los datos. Igualmente, se hace necesario capacitar y concientizar a jueces y empleados judiciales para la correcta y adecuada gestión de la información que transita a través del proceso digital. 
Desde la experiencia española (Platero, 2020 , p. 37) se describe que el sistema Lexnet no ha sido seguro y ha permitido la filtración de datos personales de los usuarios, con lo cual se ha incumplido la obligación de que los responsables de un fichero electrónico adopten las medidas técnicas y organizativas necesarias para garantizar la seguridad de datos personales y evitar su alteración, pérdida, tratamiento o acceso no autorizado.

En consecuencia, se torna necesario indagar por los instrumentos o medios más adecuados que permitan suplir los vacíos normativos que la CADH, la Constitución Política de Colombia de 1991 y el Decreto Legislativo 806 de 2020 han dejado con relación al tratamiento y protección de los datos personales de las partes de un proceso en el pretendido contexto de justicia digital que se proyecta para el país.

\section{Reglas de Heredia como base de protección de los datos personales en la justicia digital}

Las denominadas "Reglas de Heredia" del año 2003 constituyen un instrumento de soft law diseñado para suplir el vacío normativo que existía para la época sobre la forma en cómo los tribunales debían publicar su información en internet, en aras de garantizar la debida reserva judicial y el respeto a los derechos relacionados con el hábeas data de los implicados en el proceso cuya providencia se difunde. Si bien no son vinculantes para los Estados, brindan lineamentos para las políticas públicas de administración de justicia que persigan la cercanía de la justicia al ciudadano a través de sistemas digitales de tramitación de los diferentes procedimientos jurisdiccionales, observando unos mínimos de garantía de los derechos fundamentales en el marco de un proceso jurisdiccional electrónico o digitalizado.

Este instrumento de derecho blando internacional contiene una serie de medidas para la prevención de perjuicios derivados de la implementación de las TIC en el sistema judicial, con vista de uno de los principales desafíos que ofrece el respeto de los derechos humanos en los escenarios tecnológicos: la garantía del hábeas data y la debida reserva de los datos privados, semiprivados y sensibles de los partícipes procesales.

En consecuencia, se analizarán cada una de las reglas adoptadas a la luz de la experiencia colombiana.

La regla 1 consagra como finalidades de la difusión en internet de las providencias judiciales las de a) el conocimiento de la información jurisprudencial y la garantía de igualdad ante la ley; b) la transparencia de la administración de justicia; complementadas con iii) la garantía del inmediato acceso de las partes o quienes tengan un interés legítimo en la causa, a sus movimientos, citaciones o notificaciones (regla 2).

Estas finalidades se encuentran salvaguardadas desde la propia Constitución, cuyos artículos 228 y 74 predican la publicidad de las actuaciones de la administración de justicia y el derecho de toda persona de acceder a los documentos públicos con las excepciones de ley. En consecuencia, resulta admisible desde el punto de vista legal, constitucional y convencional, la incorporación de las nuevas tecnologías informáticas como herramienta de concreción de la publicidad procesal, verbigracia, a través de la comunicación de las decisiones y actuaciones judiciales por correo o por estados electrónicos. En definitiva, no existe un único medio idóneo para dar cumplimiento al principio de publicidad,

“(...) lo importante es que el tercero afectado por la decisión conozca de (su) existencia (...) sea por una comunicación (...) o bien por un conocimiento directo del aludido por la decisión (...) por la notoriedad del acto, la ejecución del mismo, o incluso la acción directa del tercero" (Sentencia C-341 de 2014).

Según la misma Corporación (Sentencia C-276 de 2019), el principio de publicidad aplica principalmente en dos momentos procesales, a saber: a) en el transcurso de las actuaciones y 
procedimientos judiciales en las que se dan a conocer a los sujetos procesales e, incluso, a la sociedad en general, sobre la existencia del mismo y su desarrollo; y, asimismo, b) cuando se ha adoptado una decisión judicial.

En el primer escenario, la publicidad procesal es prevalentemente de interés de los sujetos procesales, persiguiendo la garantía de otros derechos inherentes al debido proceso, tales como la contradicción, la defensa y la impugnación. Este estadio admite restricciones a la publicidad bajo circunstancias excepcionales sometidas a particulares cautelas para no vulnerar el derecho a la defensa. Entre ellas, las actuaciones in absentia por voluntad expresa de las partes o las que adopten medidas cautelares.

En el segundo caso, cuando ya se ha proferido providencia judicial, la publicidad incrementa su radio de acción y ya no interesa especialmente a los intervinientes del proceso sino a la comunidad en general, "supone el deber de los funcionarios judiciales de comunicar, dar a conocer y divulgar a la opinión pública o a la comunidad en general, el contenido y los efectos de sus decisiones" (Sentencia C-276 de 2019).

Esto implica que las actuaciones jurisdiccionales puedan ser conocidas por cualquier persona, para lo cual, se debe permitir el estudio y la posibilidad de revisar y estar atento a la adopción de cualquier determinación, aun sin interés directo, pudiendo obtener copias del expediente, salvo expresa reserva legal.

No obstante, otro límite a la máxima publicidad de la información judicial se encuentra en el denominado "derecho de oposición del interesado" (regla 3), según el cual, quien así lo considere podrá solicitar sin incurrir en gastos adicionales y por las razones legítimas propias de sus circunstancias, que los datos de los cuales es titular no sean objeto de difusión, con lo cual se permite su rectificación. Este derecho ha sido reconocido por la legislación colombiana en los artículos 1 y 8 numeral 1 de la Ley 1581 de 2012, en concordancia con el derecho fundamental al hábeas data consagrado en el artículo 15 Superior.

Así, la justicia digital no podrá desconocer este imperativo constitucional y legal, por lo que debe permitirse a los usuarios del sistema judicial la posibilidad de emitir su consentimiento expreso para autorizar el tratamiento de datos personales, revocar la autorización, conocer los datos que son tratados, actualizarlos, rectificarlos cuando se considere que existe deficiencia en su calidad o solicitar la supresión de datos siempre y cuando no exista una obligación legal o contractual de continuar con el tratamiento.

Para esto, dentro de los aspectos técnicos de instrumentación tecnológica del aparato jurisdiccional deberán implementarse (a) motores de búsqueda capaces de ignorar nombres y datos personales privados y sensibles en las bases de datos de las sentencias; y (b) el número único del caso o un descriptor temático como criterio de búsqueda e identificación en las bases de datos de información procesal (en conformidad con las reglas 4 y 7 ), con la finalidad de preservar la información más íntima de las personas implicadas en un proceso, con atención a la prevalencia de los derechos de privacidad e intimidad sobre el principio de publicidad en los asuntos que se refieran a niños, niñas, adolescentes (en adelante, NNA) o incapaces, así como en los casos de familia o aquellos en los que se revele el origen racial o étnico, opiniones políticas, convicciones religiosas o filosóficas, la pertenencia a sindicatos, datos relativos a la salud o la sexualidad de los implicados o cualquier otra información que pueda conllevar a su discriminación (regla 5).

Similar protección prevalente deberá atenderse en los procesos que versen sobre víctimas de violencia sexual o doméstica o cualquiera otro que goce de publicación restringida. En dichos casos, los derechos de oposición y rectificación anunciados en la regla 4 cobran mayor fuerza, por lo que deberán suprimirse, anonimizarse o incializarse dichos datos según las circunstancias e intereses de los procesados. La sentencia proferida por la Corte Interamericana de Derechos 
Humanos en el Caso V.R.P., V.P.C. y Otros vs. Nicaragua es un excelente ejemplo de inicialización como garantía de los derechos a la intimidad y privacidad de las víctimas NNA y sus familiares.

Empero, en aquellos casos relacionados con personas que voluntariamente han adquirido el carácter de públicas y los procesos versen con hechos acaecidos en virtud de tal notoriedad, deberá colegirse en sentido opuesto al anterior, de manera tal que prevalezca la publicidad en su vertiente de conocimiento por la comunidad sobre la reserva de los datos del procesado (regla 6), con lo cual se excluyen los asuntos de familia o aquellos que no tengan origen ni relación con su carácter de figura pública.

Lo anterior parte de la consideración de la justicia digital debe velar por preservar el equilibrio entre el derecho a la protección de los datos personales y la conservación de la información procesal a través de almacenamientos en la nube (hosting), ya sea implementando protocolos serios de ciberseguridad (a través de tecnologías blockchain que permitan blindar los servidores de almacenamiento judicial) o procurando la anonimización de la información reservada en las decisiones judiciales, como ya lo habían sugerido desde el 2003 las reglas bajo estudio.

Esta protección aplica no solamente durante las etapas previas a la sentencia, sino que también se exige de la providencia dictada por el juez que ponga fin al litigio. Tales providencias deberán mencionar solamente los hechos y datos personales estrictamente necesarios para fundamentar su decisión, con lo cual se evita la inclusión de hechos inconducentes o relativos a terceros, tratando no invadir la esfera íntima de las personas en ella mencionadas (regla 9).

Otro reto que representa la incorporación de las TIC en el funcionamiento del aparato jurisdiccional del Estado son los controles y registros de las bases de datos sobre infracciones, condenas y sanciones penales, que al tenor de la regla 8 solo podrán efectuarse por autoridades públicas. Sobre el particular, no puede perderse de vista el denominado "derecho al olvido" que le asiste a toda persona y que debe ser respetado tanto por las autoridades que lleven control sobre dichos registros de información como por los motores de búsqueda que faciliten su consulta.

Basado en la finalidad resocializadora de la pena, tal derecho ha sido entendido como el deber del Estado de garantizar la supresión de toda la información que vincule con una causa penal determinada a quien ya haya cumplido su condena o en cuyo favor haya prescrito la pena, salvo los eventos en que la ley consagre publicidad permanente de dicha información. Así, tras el cumplimiento de las sanciones impuestas de conformidad con el ordenamiento penal, deberá eliminarse toda información pública que impida una efectiva reinserción social y comunitaria, con lo cual se favorecen prácticas discriminatorias de quien ha superado sus problemas con la ley.

No obstante, un débil control sobre las bases de datos de sanciones y condenas penales aunada a labores inescrupulosas por parte de los medios de comunicación podrían conllevar a revivir asuntos de justicia concluidos por un sujeto, de manera tal que se afecte notoriamente su "derecho al olvido" y se limiten sus posibilidades de reinserción social. Esto constituye uno de los mayores retos que deberán afrontar las autoridades públicas en colaboración con los particulares que administren motores de búsqueda y medios comunicativos, aplicando extensivamente la regla 10, según la cual, las ediciones jurídicas deben observar a plenitud las Reglas de Heredia.

La aplicación estricta de los parámetros derivados de cada una de las reglas analizadas conllevará a la adecuación del sistema jurisdiccional colombiano a las exigencias de la cuarta revolución industrial, especialmente relevante en el contexto generado por la pandemia del COVID-19. 
1 Término acuñado por Klaus Schwab para referirse a la implementación de mecanismos ciberfísicos en las relaciones contemporáneas, con preeminencia de escenarios que incorporan la infraestructura física con las TIC tales como la Inteligencia Artificial (IA), el Machine Learning, el internet de las cosas, la minería de datos o el blockchain. Para Schawb (2016), esta revolución se caracteriza por "una fusión de tecnologías actualmente en prueba o en desarrollo (...) desintegrando las fronteras entre las esferas física, digital, y biológica".

2 Categoría dada a las dinámicas sociales en las que las TIC facilitan la creación, distribución y manipulación de la información; con incidencia en las relaciones sociales, culturales y económicas. Propugna por el uso común de la información y el conocimiento para la promoción del desarrollo sostenible y la mejora de la calidad de vida.

3 Artículo 6. Tratamiento de datos sensibles. Se prohíbe el Tratamiento de datos sensibles, excepto cuando: (...) d) El Tratamiento se refiera a datos que sean necesarios para el reconocimiento, ejercicio o defensa de un derecho en un proceso judicial (...). (Ley 1581 de 2012).

4 Para una mayor explicación sobre la solución de controversias en línea, Cf. Bustamante Rúa, M.; Ángel Muñoz, S.; Giraldo Aristizábal, J. \& Marín Tapiero, J. (2020). Solución de Conflictos (MASC) e Inteligencia Artificial (IA) para la Solución de Controversias en Línea (SCL): Una Apuesta por la Descongestión en la Administración de Justicia. The Law, State and Telecommunications Review, 12(1), pp. 77-112.

5 En idéntico sentido se pronunció el máximo tribunal interamericano en las sentencias de los casos J. vs. Perú (27 de noviembre de 2013) y Girón y Otro vs. Guatemala (15 de octubre de 2019).

6 Debe acotarse el tratamiento casi sinonímico que en la jurisprudencia y doctrina nacionales se la ha dado a los conceptos de "privacidad" (de origen anglosajón) e "intimidad" (propio de la tradición normativa continental). Esto se observa en las sentencias de la Corte Constitucional C-602 de 2016, M. P. Alejandro Linares Cantillo; T-364 de 2018, M. P. Alberto Rojas Ríos; T-155 de 2019, M. P. Diana Fajardo Rivera y C-094 de 2020, M. P. Alejandro Linares Cantillo. Su diferencia ha radicado en el tratamiento general de la "privacidad" a partir de la diferenciación entre "lo público" y "lo privado", para luego extraer los contornos del derecho a la "intimidad" como parte de la privacidad. Para este tribunal constitucional, "la definición de aquello que es público o privado se encuentra en la base de la discusión acerca del alcance del derecho a la intimidad (...) el concepto de 'privacidad' o 'de lo privado', corresponde a los asuntos que en principio tocan exclusivamente con los intereses propios y específicos de la persona humana, sin que afecten o se refieran a los demás miembros de la colectividad" (Sentencia C-602 de 2016). Por consiguiente, el derecho a la intimidad permite a su titular el disfrute sin interferencias arbitrarias de terceros de su espacio privado -que bien puede ser personal, familiar, social o gremial-. En la Sentencia C-489 de 1995, M. P. Eduardo Cifuentes Muñoz, la Corte Constitucional definió a la intimidad como "un derecho de status negativo, o de defensa frente a cualquier invasión indebida de la esfera privada, a la vez que un derecho de status positivo, o de control sobre las informaciones que afecten a la persona o la familia (...) impide la divulgación ilegítima de hechos o documentos privados (y se materializa) como libertad, que se realiza en el derecho de toda persona a tomar las decisiones que conciernen a la esfera de su vida privada". En consecuencia, el derecho a la intimidad confiere a su titular la facultad de oponerse a la intromisión injustificada en la órbita que se ha reservado para sí o su familia, a la divulgación injustificada de los hechos privados o a las restricciones injustificadas a su libertad de tomar las decisiones acerca de asuntos que solo le conciernen a la persona. También impone a las autoridades y particulares el deber de abstenerse de ejecutar actos que impliquen la intromisión injustificada en la órbita privada de las personas, la divulgación de los hechos privados o la restricción injustificada de la libertad de elegir en asuntos que solo le conciernen a la persona o a su familia (Corte Constitucional, Sentencia C-602 de 2016). Sobre los orígenes diferenciados de ambos derechos, Cf. Abril, P. y Pizarro, E. (2014). La intimidad europea frente a la privacidad americana. Una visión comparativa del derecho al olvido. InDret Revista para el análisis del Derecho, pp. 1-62; y Chirino, A. (1998). Protección de datos y moderno proceso penal. Aspectos constitucionales y legales. 
7 Original en inglés. Traducción propia de los autores.

8 Según Basterra (2016), entre la intimidad y la privacidad existe una relación de género (privacidad) a especie (intimidad). "Vale decir que lo íntimo es más íntimo que lo privado y, si bien se pueden utilizar como sinónimos en muchos casos, son conceptos diferentes" (Basterra, 2016, p. 150). Por consiguiente, "todo individuo tiene la misma protección en relación con el derecho a la intimidad (...) sin embargo, no todos los sujetos tienen la misma protección respecto de su privacidad, dado que un funcionario o personaje público tendrá una expectativa menor de privacidad que alguien anónimo o desconocido" (Basterra, 2016, pp. 150-151).

9 Original en portugués. Traducción propia de los autores.

10 Original en portugués. Traducción propia de los autores.

11 "Consisten en un conjunto de procedimientos lógicos que permiten que las computadoras apoyen a los humanos en la tarea de analizar situaciones y adoptar decisiones, a través de la ingeniería del conocimiento que se alimenta de las estrategias del experto en el Derecho y busca formularlos en reglas perfectamente enunciables" (Bustamante, Ángel, Giraldo y Marín, 2020, p. 97). Cf. Trazegnies, F. (2013). ¿Seguirán existiendo jueces en el futuro? El razonamiento judicial y la inteligencia artificial. lus Et Veritas (47), pp. 112-130; y Cáceres, E. (2006). Inteligencia Artificial, Derecho y E-Justice (El Proyecto lij-Conacyt). Boletín Mexicano de Derecho Comparado (116), 593-611.

12 En similar sentido, pero haciendo énfasis en el ordenamiento jurídico brasileño: Gregório y Paiva (2004). Para un mayor análisis sobre la necesaria protección de datos en el proceso electrónico, Cf. Araújo Almeida Filho, J. y de Souza Meirelles, D. (2014). A Necessária Ponderação de Princípios na Publicidade Processual. Em: L. F. Coelho; R T. Michaloski Alves; S. Casali Rocha. (Org.), Direitos Humanos e Novos Direitos na Contemporaneidade, 1 ed., pp. 45-68. Grafisul.

13 Está relacionado con el "principio de caducidad del dato negativo" a la luz de la jurisprudencia de la Corte Suprema de Justicia colombiana. Así, puede verse en la Sentencia de la Sala de Casación Penal con radicado número 20889 del 19 de agosto de 2015. Un igual tratamiento recibió por parte de la Corte Constitucional colombiana en Sentencia SU-458 de 2012. Para un análisis más detenido sobre las implicaciones del derecho al olvido, Cf. De Terwangne, C. (2012). Privacidad en Internet y el derecho a ser olvidado/derecho al olvido. Revista de Internet, Derecho y Política, 13, pp. 53-66.

14 Especialmente, en aquellos casos en los que se utiliza a los mass media como instrumento de campaña negativa o instigación. Así lo manifiesta Leturia (2017, p. 33): "hay y habrá casos en que es posible imaginar motivaciones específicas para montar una campaña mediática, cuyos objetivos son, en ocasiones, gravemente contrarios al ordenamiento institucional y por lo mismo ameritan una especial atención y regulación".

15 Esta interpretación extensiva es posible a la luz del segundo alcance consagrado en las citadas Reglas de Heredia de 2003, según las cuales las organizaciones o las empresas que difundan información judicial en Internet podrán utilizar procedimientos más rigurosos de protección, como la exigibilidad de su observancia por todo aquel que tenga acceso a información judicial por medios virtuales. 


\section{Referencias}

Abril, P. y Pizarro, E. (2014). La intimidad europea frente a la privacidad americana. Una visión comparativa del derecho al olvido. InDret Revista para el análisis del Derecho, pp. 1-62. Disponible en: https://www.derechoaleer.org/media/files/olvido/1031.pdf

Allende Pérez de Arce, J. (2019). Tribunales civiles en Línea: Una propuesta para introducirlos sin afectar el derecho a acceder a la justicia de quienes no están conectados a internet. Revista Chilena de Derecho y Tecnología, 8(1), pp. 185-206. Disponible en: https://scielo.conicyt.cl/pdf/rchdt/ v8n1/0719-2584-rchdt-8-1-00185.pdf

Amrani-Mekki, S. (2008). El impacto de las nuevas tecnologías sobre la forma del proceso civil. En: F. Carpi y M. Ortells Ramos, Oralidad y escritura en un proceso civil eficiente: Coloquio de la Asociación Internacional de Derecho Procesal, pp. 93-133.

Araújo Almeida Filho, J. y de Souza Meirelles, D. (2014). A Necessária Ponderação de Princípios na Publicidade Processual. Em: L. F. Coelho; R T. Michaloski Alves; S. Casali Rocha. (Org.), Direitos Humanos e Novos Direitos na Contemporaneidade, 1 ed., pp. 45-68. Disponible en: https://www.academia.edu/30977440/A_Necess\%C3\%A1ria_Pondera\%C3\%A7\%C3\%A3o_ de_Princ\%C3\%ADpios_na_Publicidade_Processual

Asamblea General de las Naciones Unidas (2011). Informe del relator especial sobre la promoción y protección del derecho a la libertad de opinión y de expresión, Frank La Rue. Disponible en: https://www.acnur.org/fileadmin/Documentos/BDL/2015/10048.pdf?view=1

Basterra, M. (2016). Derecho a la intimidad, privacidad y confidencialidad en la ciudad autónoma de Buenos Aires. En: M. Basterra (Coord.). Poder judicial de la ciudad de Buenos Aires; Consejo de la Magistratura, Constitución de la Ciudad Autónoma de Buenos Aires. Edición comentada, pp. 141-157. Disponible en: https://archivos.juridicas.unam.mx/www/bjv/libros/9/4496/11.pdf

Bustamante Rúa, M., Ángel Muñoz, S., Giraldo Aristizábal, J. y Marín Tapiero, J. (2020). Solución de Conflictos (MASC) e Inteligencia Artificial (IA) para la Solución de Controversias en Línea (SCL): Una Apuesta por la Descongestión en la Administración de Justicia. The Law, State and Telecommunications Review, 12(1), pp. 77-112. Disponible en: https://doi.org/10.26512/ Istr.v12i1.25808

Bustamante, M. y Marín, J. (2020). Justicia digital y proceso electrónico en Colombia. En: Diana Ramírez (coord.), Justicia Digital. Un análisis internacional en época de crisis, pp. 418-458. Editorial Justicia y Proceso.

Bygrave, L. (2010). Privacy and Data Protection in an International Perspective. Stockholm Institute for Scandinavian Law. Disponible en: https://www.uio.no/studier/emner/jus/jus/JUS5630/v13/ undervisningsmateriale/privacy-and-data-protection-in-international-perspective.pdf

Cáceres, E. (2006). Inteligencia Artificial, Derecho y E-Justice (El Proyecto lij-Conacyt). Boletín Mexicano de Derecho Comparado (116), pp. 593-611. Disponible en: http://www.scielo.org.mx/pdf/ bmdc/v39n116/v39n116a12.pdf

Chirino, A. (1998). Protección de datos y moderno proceso penal. Aspectos constitucionales y legales. Revista de Ciencias Jurídicas, pp. 9-41. Disponible en: https://revistas.ucr.ac.cr/index.php/ juridicas/article/view/13723

Congreso de la República de Colombia. Ley 270 de 1996. Estatutaria de la Administración de Justicia. Diario Oficial No. 42.745.

Congreso de la República de Colombia. Ley 1581 de 2012. Por la cual se dictan disposiciones generales para la protección de datos personales. Diario Oficial No. 48.587. 
Corte Constitucional. (16 de febrero de 1995) Sentencia C-053 de 1995 (M. P. Eduardo Cifuentes Muñoz).

Corte Constitucional. (2 de noviembre de 1995) Sentencia C-489 de 1995 (M. P. Eduardo Cifuentes Muñoz).

Corte Constitucional. (31 de enero de 2001) Sentencia C-096 de 2001 (M. P. Álvaro Tafur Galvis).

Corte Constitucional. (21 de junio de 2012) Sentencia SU-458 de 2012 (M. P. Adriana María Guillén Arango).

Corte Constitucional. (2 de noviembre de 2016) Sentencia C-602 de 2016 (M. P. Alejandro Linares Cantillo).

Corte Interamericana de Derechos Humanos. (22 de noviembre de 2005) Caso Palamara Iribarne vs. Chile.

Corte Interamericana de Derechos Humanos (27 de noviembre de 2013) Caso J. vs. Perú.

Corte Interamericana de Derechos Humanos. (15 de octubre de 2019) Caso Girón y Otro vs. Guatemala.

Corte Suprema de Justicia, Sala de Casación Penal. Sentencia del 19 de agosto de 2015, Radicado No. 20889 (M. P. Patricia Salazar Cuellar).

De Terwangne, C. (2012). Privacidad en Internet y el derecho a ser olvidado/derecho al olvido. Revista de Internet, Derecho y Política, 13, pp. 53-66. Disponible en: https://www.redalyc.org/ pdf/788/78824460006.pdf

Díaz, A. (2013). La autorregulación en redes sociales como forma de garantizar los derechos de intimidad, privacidad y protección de datos personales. Revista Internacional Online de Derecho de la Comunicación, 13, pp. 125-143. Disponible en: https://dialnet.unirioja.es/descarga/ articulo/4330473.pdf

Doneda, D. (2011). A proteção dos dados pessoais como um direito fundamental. Revista Espaço Jurídico, 12(2), pp. 91-108.

Echavarría, M. (2020). La "justicia digital": del término común al concepto especializado. En: Diana Ramírez (coord.), Justicia Digital. Un análisis internacional en época de crisis, pp. 401-417. Editorial Justicia y Proceso.

Gacitúa, A. (2014). El derecho fundamental a la protección de datos personales en el ámbito de la prevención y represión penal europea (en busca del equilibro entre la libertad y la seguridad). Tesis de Doctorado, Universidad Autónoma de Barcelona. https://ddd.uab.cat/pub/tesis/2014/ hdl_10803_284352/alge1de1.pdf

International Development Research Centre - IDRC (2003). Reglas mínimas para la difusión de información judicial en internet, Reglas de Heredia. Disponible en: http://www.iijusticia.org/heredia/Reglas_ de_Heredia.htm

Leturia, F. (2017). La problemática de los juicios paralelos en la jurisprudencia y doctrina española. Revista lus et Praxis, 23(2), pp. 21-50.

Linden Ruaro, R.; Piñeiro Rodríguez, D. y Finger, B. (2011). O direito à proteção de dados pessoais e a privacidade. Revista da Faculdade de Direito - UFPR (47), pp. 45-66.

Miranda Bonilla, H. (2016). Acceso a Internet como derecho fundamental. Revista Jurídica IUS Doctrina, (15), pp. 1-23. Disponible en: https://revistas.ucr.ac.cr/index.php/iusdoctrina/article/ view/27476/27648

Ministerio de Justicia y del Derecho de Colombia. Decreto Legislativo 806 de 2020. Por el cual se adoptan medidas para implementar las tecnologías de la información y las comunicaciones en las actuaciones judiciales, agilizar los procesos judiciales y flexibilizar la atención a los usuarios 
del servicio de justicia, en el marco del Estado de Emergencia Económica, Social y Ecológica. Diario Oficial No. 51.335.

Organización de los Estados Americanos (1969). Convención Americana sobre Derechos Humanos. Disponible en: https://www.oas.org/dil/esp/tratados_b-32_convencion_americana_sobre_ derechos_humanos.htm

Picó i Junoy, J. (2012). Las garantías constitucionales del proceso. Bosch Editor.

Platero, A. (2020). Lexnet como máximo exponente del sistema de justicia electrónica en España: Especial referencia a su tratamiento de datos personales. Revisa de Ciencias Jurídicas, 152 (13-42), pp. 13-42. Disponible en: https://revistas.ucr.ac.cr/index.php/juridicas/article/view/42568/42825

Prince Torres, Á. (2020). El acceso a internet como derecho fundamental: perspectivas internacionales. Revista Justicia y Derecho, 3(1), pp. 1-19. Disponible en: https://revistas.uautonoma.cl/index. php/rjyd/article/view/456/559

Red Iberoamericana de protección de datos (2017). Estándares de protección de datos personales para los Estados Iberoamericanos. Disponible en: https://www.redipd.org/sites/default/files/inlinefiles/Estandares_Esp_Con_logo_RIPD.pdf

Rincón Martínez, K. y Ramírez Severiche, C. (2017). Relación entre el derecho al acceso a la información y el derecho a la intimidad y privacidad en la justicia digital. Revista Cultural Unilibre, No. 1, pp. 47-55. Universidad Libre de Colombia. Disponible en: https://revistas. unilibre.edu.co/index. php/revista_cultural/article/view/4207/3562

Rodríguez Rescia, V. (1998). El debido proceso legal y la Convención Americana sobre Derechos Humanos. Disponible en: http://www.corteidh.or.cr/tablas/a17762.pdf

Schwab, K. (2016). La cuarta revolución industrial. Editorial Debate.

Trazegnies, F. (2013). ¿Seguirán existiendo jueces en el futuro? El razonamiento judicial y la inteligencia artificial. lus Et Veritas (47), pp. 112-130. Disponible en: http://revistas.pucp.edu.pe/index.php/ iusetveritas/article/view/11938/12506 